\title{
Oxidant and antioxidant status in coronary artery disease
}

\author{
ABDOLHOSSEIN BASTANI $^{1}$, SADEGH RAJABI $^{1}$, AFSHIN DALIRAN $^{1}$, \\ HABIBOLLAH SAADAT $^{2}$ and FERIDOUN KARIMI-BUSHERI ${ }^{3}$ \\ ${ }^{1}$ Department of Clinical Biochemistry, School of Medicine, Shahid Beheshti University of Medical Sciences, \\ Tehran 1985717443; ${ }^{2}$ Cardiovascular Research Center, Modares Hospital, Shahid Beheshti University \\ of Medical Sciences, Tehran 1998734383, Iran; ${ }^{3}$ Department of Oncology, \\ University of Alberta, Edmonton, AB T6G 1Z2, Canada
}

Received February 26, 2018; Accepted June 25, 2018

DOI: $10.3892 /$ br.2018.1130

\begin{abstract}
Formation of atherosclerotic plaques is the major cause of coronary artery disease (CAD). Several lines of study have revealed the role of oxidative stress in CAD pathogenesis. In the present study the aim was to investigate the oxidative and antioxidative markers in CAD patients and a control population. The study sample comprised of acute coronary syndrome (ACS) patients, chronic CAD patients and healthy controls ( $n=30$ /group). Blood samples of patients and control subjects were collected to measure the concentrations of reduced glutathione (GSH), malondialdehyde (MDA) and the percentage of MDA release as well as the activity of erythrocyte glutathione peroxidase (GPx) and total antioxidant capacity (TAC) of plasma. All parameters were measured by spectrophotometric methods. Additionally, oxidant/antioxidant status was compared between CAD patients with single, double or triple-vessel stenosis and in comparison with controls. The results indicated a significant increase in MDA level and the percentage of MDA release $(\mathrm{P}<0.05)$, and a marked decrease in GSH concentration $(\mathrm{P}<0.0001)$, TAC $(\mathrm{P}<0.0001)$ and the activity of erythrocyte GPx $(\mathrm{P}<0.0001)$ in the patient groups compared controls. ACS patients exhibited a similar pattern of data when compared with the chronic CAD group. Similar results were also observed when chronic CAD patients with single, double or triple vessel stenosis and controls were compared. The present study indicates that the acute form of CAD is more susceptible to oxidative damage,
\end{abstract}

Correspondence to: Dr Feridoun Karimi-Busheri, Department of Oncology, University of Alberta, 11560 University Avenue, Edmonton, AB T6G 1Z2, Canada

E-mail: fkarimi@ualberta.ca

Dr Abdolhossein Bastani, Department of Clinical Biochemistry, School of Medicine, Shahid Beheshti University of Medical Sciences, Building 3, Kodkyar Street, Daneshjou Boulevard, Tehran 1985717443, Iran

E-mail: ab_bastani2002@yahoo.com

Key words: coronary artery disease, acute coronary syndrome, oxidative stress, glutathione peroxidase, malondialdehyde suggesting that use of antioxidant therapy may be warranted to ameliorate oxidative stress in this condition.

\section{Introduction}

Coronary artery disease (CAD) comprises the largest proportion of cardiovascular diseases (CVDs) and accounts for more than one third of all mortalities worldwide (1). Risk factors include hypertension, cigarette smoking, type 2 diabetes mellitus, increased cholesterol concentration and obesity (2). Atherosclerosis, the formation of plaque inside the arteries, is the main cause of CAD (3). Several pathological events contribute to atherosclerosis, including endothelial dysfunction, extensive lipid deposition in the tunica intima, exacerbated innate and adaptive immune responses, vascular smooth muscle cell proliferation and remodeling of the extracellular matrix (4).

Two major hypotheses have been proposed to describe the origin of atherosclerosis: i) the thrombogenic theory, which suggests that thickening of the intima layer of vessels is a result of the organization of fibrin by fibroblasts, associated with secondary lipid enrichment; and ii) the lipogenic theory, which suggests that the deposition of lipid inside the arterial walls is caused by an imbalance between the mechanisms responsible for lipid accumulation and removal (5-7). To date, several lines of study have indicated a role for oxidative stress in atherosclerosis and CVDs (8-11). Oxidative stress is the result of enhanced production of reactive oxygen species (ROS), which are the key molecules in the signaling pathways implicated in vascular inflammation in atherogenesis, starting from the initiation of fatty streak formation to lesion progression and plaque rupture (12). ROS are established to damage the fundamental biomolecules in cells including DNA, proteins and lipids (13). A previous report demonstrated that oxidative modification of low-density lipoprotein (LDL) is a key mechanism rendering lipoproteins atherogenic (14). Furthermore, it has been reported that lipid peroxidation produces unsaturated aldehydes including acrolein and malondialdehyde (MDA), which exert toxic effects due to their reactivity with nucleophile compounds and their ability to produce protein and DNA adducts without prior metabolic activation (15). These aldehydes are considered to function as mediators of inflammation and vascular dysfunction (15).

On the other hand, there are several antioxidant systems grouped as enzymatic and non-enzymatic antioxidant systems. 
Antioxidant enzymes include catalase and glutathione peroxidase (GPx), superoxide dismutase and glutathione reductase (GR), while glutathione (GSH), vitamins A, E and C and uric acid are major non-enzymatic antioxidants (16).

The intent of the present study was to determine the oxidative and antioxidative markers in patients with CAD and to compare these parameters between patient and healthy volunteer groups. It also aimed to compare oxidant/antioxidant status in chronic CAD patients with single, double or triple vessel stenosis.

\section{Materials and methods}

Patients. The study sample consisted of 90 subjects who were divided into three equal groups: patients with acute coronary syndrome (ACS), patients with chronic CAD and healthy subjects as controls. Each group comprised of 30 subjects (20 male and 10 female aged 40-70 years). ACS subjects were selected from patients hospitalized at the Coronary Care Unit (CCU) of Modares Hospital in Tehran, Iran, due to angina pectoris or acute myocardial infarction. CAD patients were selected from patients referred to the Angiography Unit of Modares Hospital and healthy subjects from Modares Hospital were included in the study as controls. All patients were enrolled from June to November, 2012. All patients signed informed consent forms agreeing to their participation in the study. No subject had any other disease or was taking medications. The study was conducted following approval by the Ethics Committee of Shahid Beheshti University of Medical Sciences (Tehran, Iran; approval no. IR.SBMU. REC.1387.134). Clinical and laboratory data of the patients and controls are presented in Table I.

Sample collection. Blood samples $(10 \mathrm{ml})$ were collected into EDTA sterile plastic tubes. All samples were centrifuged at $2,000 \mathrm{x}$ g for $10 \mathrm{~min}$ at $4^{\circ} \mathrm{C}$, and were maintained at $-70^{\circ} \mathrm{C}$ until measurement of plasma total antioxidant capacity (TAC). For determination of GPx activity as well as GSH and MDA levels, the obtained packed red blood cells (pRBC) were washed with normal saline and phosphate-buffered saline (PBS), respectively, and then stored at $-70^{\circ} \mathrm{C}$ until further analysis.

Measurement of erythrocyte GSH concentration. GSH level was measured using 5, 5'-dithiobis-(2-nitrobenzoate) (DTNB; Merck KGaA, Darmstadt, Germany) according to the spectrophotometric method described by Beutler et al (16). Briefly, $0.2 \mathrm{ml}$ of pRBCs was mixed with $8 \mathrm{ml}$ PBS $(0.2 \mathrm{M}$; $\mathrm{pH}$ 7.4) and centrifuged at $25,000 \mathrm{xg}$ for $5 \mathrm{~min}$ at $4^{\circ} \mathrm{C}$. The sample was then mixed with $0.5 \mathrm{ml}$ DTNB. For each GSH test, $0.1 \mathrm{ml} \mathrm{pRBC}$ suspension was mixed with $0.9 \mathrm{ml}$ distilled water to provide hemolysate. Subsequently, the mixture was vortexed and absorbance was measured at $412 \mathrm{~nm}$ to detect the GSH content. The GSH levels were expressed per gram of hemoglobin $(\mathrm{Hb} ; \mu \mathrm{mol} / \mathrm{gHb})$. The quantity of GSH was determined by the known molar extinction coefficient of GSH $\left(1.36 \times 10^{4} \mathrm{~mol}^{-1} \mathrm{~cm}^{-1}\right)(16)$.

Determining the susceptibility of RBC to oxidative stress. Plasma MDA is a naturally occurring product of lipid peroxidation usually measured based on levels of thiobarbi-
Table I. Biochemical parameters of patients and control subjects included in the study.

\begin{tabular}{lccc}
\hline & \multicolumn{3}{c}{ Study group (n=30/group) } \\
\cline { 2 - 4 } & $\begin{array}{c}\text { ACS } \\
\text { patients }\end{array}$ & $\begin{array}{c}\text { Chronic CAD } \\
\text { patients }\end{array}$ & $\begin{array}{c}\text { Healthy } \\
\text { controls }\end{array}$ \\
\hline Parameter & 65 & 63 & 61 \\
Age & $246 \pm 21$ & $194 \pm 22$ & $178 \pm 16$ \\
Cholesterol, mg/dl & $222 \pm 21$ & $162 \pm 15$ & $129 \pm 9$ \\
Triglyceride, mg/dl & $295 \pm 20$ & $118 \pm 15$ & $94 \pm 11$ \\
Creatine kinase, IU/1 & $63 \pm 10$ & $345 \pm 7$ & $20 \pm 8$ \\
Creatine kinase-MB, IU/1 & $43 \pm 7$ & $48 \pm 5$ & $52 \pm 5$ \\
$\begin{array}{l}\text { High-density } \\
\text { lipoprotein, mg/dl }\end{array}$ & $158 \pm 22$ & $105 \pm 25$ & $100 \pm 8$ \\
$\begin{array}{l}\text { Low-density } \\
\text { lipoprotein, mg/dl }\end{array}$ & & & \\
$\begin{array}{l}\text { Diastolic blood } \\
\text { pressure, mmHg }\end{array}$ & $155 \pm 8$ & $145 \pm 4$ & $127 \pm 9$ \\
$\begin{array}{l}\text { Systolic blood } \\
\text { pressure, mmHg }\end{array}$ & $111 \pm 7$ & $96 \pm 8$ & $85 \pm 7$ \\
\hline
\end{tabular}

ACS, acute coronary syndrome; CAD; coronary artery disease.

turic acid (TBA) reactive substances or lipid peroxides (17). pRBCs were diluted $(1: 8 \mathrm{v} / \mathrm{v})$ with $0.9 \%$ saline. According to a method reported by Stocks and Dormandy for induction of oxidative conditions, the RBCs were incubated with $4 \mathrm{mM}$ $\mathrm{H}_{2} \mathrm{O}_{2}$ at $37^{\circ} \mathrm{C}$, in a shaking thermostatic bath for $120 \mathrm{~min}$, either in the absence or presence of $2 \mathrm{mM}$ sodium azide (as a potent inhibitor of RBC catalase; Merck $\mathrm{KGaA}$ ). A 'zero time' sample was obtained by terminating the reaction [with arsenite-trichloroacetic acid (TCA) solution (Merck KGaA)] immediately following addition of $4 \mathrm{mM} \mathrm{H}_{2} \mathrm{O}_{2}$. This sample was also treated by $\mathrm{H}_{2} \mathrm{O}_{2}$ either in the absence or presence of $2 \mathrm{mM}$ sodium azide. Healthy control samples were also incubated in the same conditions to assess the extent of spontaneous oxidation of RBC. Following addition of arsenite-TCA solution and centrifugation at $4,400 \mathrm{xg}$ at $4^{\circ} \mathrm{C}$ for $5 \mathrm{~min}, 2 \mathrm{ml}$ supernatant was added to TBA-containing tubes. All tubes were then placed in a $100^{\circ} \mathrm{C}$ bath for $15 \mathrm{~min}$, and finally, the absorbance of the samples was measured spectrophotometrically at $535 \mathrm{~nm}$. 1,1,3,3-tetraethoxy-propane was used as a standard. The results were reported as nmol/gHb. The concentration of blood $\mathrm{Hb}$ was measured by the cyanmethemoglobin method described by Amatuzio et al (18). The percentage of MDA release from erythrocyte membranes was calculated by the following formula: Concentration of MDA without sodium azide/concentration of MDA with sodium azide x100 (19).

Determination of erythrocyte GPx activity. The GPx activity of erythrocytes was measured by the modified method of Andersen et al (20), which is based on spectrophotometric monitoring of the decrease in absorbance of NADPH (Fluka Chemie GmbH; Sigma-Aldrich; Merck KGaA) at $340 \mathrm{~nm}$ in the presence of GR (Sigma-Aldrich; Merck KGaA). This method is based on GPx oxidizing GSH to oxidized GSH, which is then reduced by GR; finally, oxidation of NADPH 
to $\mathrm{NADP}^{+}$leads to the steady decrease in absorbance of NADPH (21). GPx activities of erythrocytes were expressed in $\mathrm{U} / \mathrm{gHb}$ in hemolysate.

TAC of plasma. TAC of plasma was measured by the method of Miller et al (22) using a Total Antioxidant Status kit (Randox Laboratories Ltd., Crumlin, UK). According to this method, 2,2'-azino-bis (3-ethylbenzothiazoline-6-sulfonate) (ABTS; Merck $\mathrm{KGaA}$ ) is incubated with metmyoglobin (Merck KGaA) and $\mathrm{H}_{2} \mathrm{O}_{2}$ to form the radical cation $\mathrm{ABTS}^{+\bullet}$, the absorbance of which can be measured at $600 \mathrm{~nm}$. In this method, the capacity of plasma antioxidants to inhibit this reaction is measured and compared with 6-hydroxy-2,5,7,8-tetramethylchroman-2-carboxylic acid (Trolox; Merck KGaA) as a standard. Briefly, $1 \mathrm{ml}$ chromogen (601 $\mu \mathrm{M}$ metmyoglobin and $610 \mu \mathrm{M}$ ABTS) was added to $50 \mu \mathrm{l}$ plasma sample and mixed with $350 \mu \mathrm{l}$ of $2,500 \mu \mathrm{M} \mathrm{H}_{2} \mathrm{O}_{2}$. The mixture was incubated at $37^{\circ} \mathrm{C}$ for $3 \mathrm{~min}$ and its absorbance at $600 \mathrm{~nm}$ read. Values were expressed in $\mathrm{mmol} / \mathrm{l}$.

Statistical analysis. Data were expressed as the mean \pm standard error of the mean. The data were analyzed using SPSS version 19.0 software (IBM Corp., Armonk, NY, USA). To compare the difference between the three groups, data were analyzed by one-way analysis of variance (ANOVA). Scheffe's test was used post hoc to assess the significance of differences among the groups. Additionally, to assess the association between the number of stenotic vessels and oxidative status in chronic CAD patients, the 30 patients with chronic CAD were divided into three equal groups ( $n=10 /$ group) as follows: patients with one stenotic vessel, patients two stenotic vessels and patients with three vessel stenoses. The 30 healthy subjects were included in the analysis as the control group, and ANOVA and Scheffe's test were used as above. In all analyses $\mathrm{P}<0.05$ was considered to indicate statistical significance.

\section{Results}

Comparison of erythrocyte GSH levels between the three subject groups. Fig. 1 depicts the level of GSH measured in RBCs from healthy controls and the groups of patients, where the capacity to overcome an oxidative stress has been evaluated. The concentrations of erythrocyte GSH in the three groups were as follows: ACS patients, $6.14 \pm 0.88 \mu \mathrm{mol} / \mathrm{gHb}$; chronic CAD patients, $6.91 \pm 0.73 \mu \mathrm{mol} / \mathrm{gHb}$ and healthy controls, $10.63 \pm 0.48 \mu \mathrm{mol} / \mathrm{gHb}$. As the results indicate, the levels of erythrocyte GSH in ACS and chronic CAD patients was significantly lower than in healthy controls $(\mathrm{P}<0.0001)$. In addition, the level in ACS patients was significantly lower compared with in chronic CAD patients $(\mathrm{P}<0.0001)$.

Comparison of RBC susceptibility to oxidative stress in the three study groups. Table II presents the levels of MDA measured in RBCs of the two patient groups and of healthy controls following incubation with $\mathrm{H}_{2} \mathrm{O}_{2}$ for $120 \mathrm{~min}$ and at zero time, either in the presence or absence of sodium azide. MDA levels in the presence of sodium azide at the incubation time of $120 \mathrm{~min}$ were as follows: in ACS patients, $988 \pm 52 \mathrm{nmol} / \mathrm{gHb}$; in chronic CAD patients, $873 \pm 48 \mathrm{nmol} / \mathrm{gHb}$; and in healthy controls, $409 \pm 24 \mathrm{nmol} / \mathrm{gHb}$. As can be observed, these levels

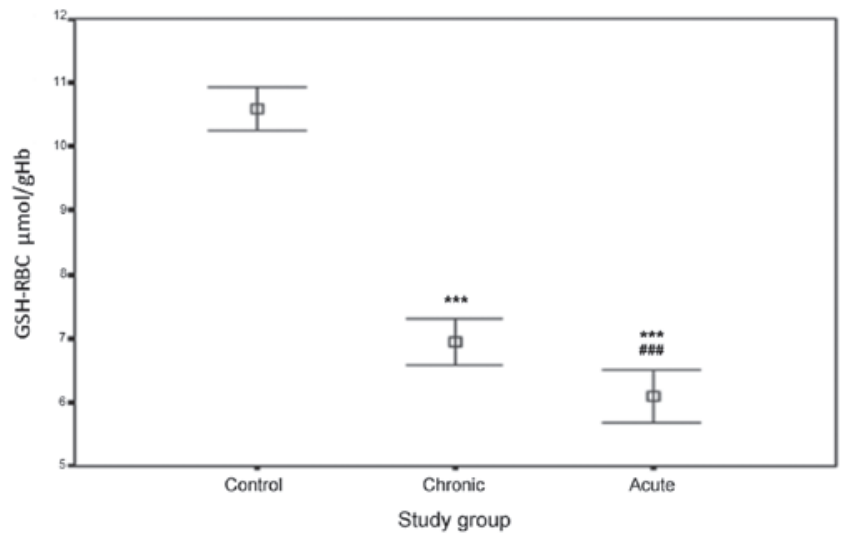

Figure 1. Concentration of erythrocyte GSH in patients with ACS and chronic coronary disease compared with healthy controls. Data are expressed as means \pm standard error of the mean. ${ }^{* * *} \mathrm{P}<0.0001$ vs. control;

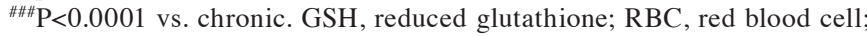
$\mathrm{gHb}$, gram of hemoglobin; ACS, acute coronary syndrome.

Table II. Levels of MDA in the presence or absence of sodium azide at zero time and 120 min after incubation with $\mathrm{H}_{2} \mathrm{O}_{2}$.

\begin{tabular}{|c|c|c|c|c|}
\hline & $\begin{array}{l}\mathrm{MDA}-\mathrm{SA} \\
\mathrm{nmol} / \mathrm{gHb}\end{array}$ & $\begin{array}{l}\text { MDA-SA, } \\
\mathrm{nmol} / \mathrm{gHb}\end{array}$ & $\begin{array}{c}\text { MDA, } \\
\mathrm{nmol} / \mathrm{gHb}\end{array}$ & $\begin{array}{c}\text { MDA, } \\
\mathrm{nmol} / \mathrm{gHb}\end{array}$ \\
\hline (n=30/group) & $120 \mathrm{~min}$ & Zero time & $120 \mathrm{~min}$ & Zero time \\
\hline Control & $409 \pm 24$ & $246 \pm 20$ & $173 \pm 19$ & $108 \pm 9$ \\
\hline $\begin{array}{l}\text { Chronic CAD } \\
\text { patients }\end{array}$ & $873 \pm 48^{b}$ & $463 \pm 28$ & $490 \pm 33$ & $286 \pm 22$ \\
\hline ACS patients & $988 \pm 52^{\mathrm{a}}$ & $512 \pm 37$ & $633 \pm 39$ & $312 \pm 26$ \\
\hline
\end{tabular}

All data are expressed as means \pm standard error of the mean, $\mathrm{n}=30$ /group. ${ }^{\mathrm{a}} \mathrm{P}<0.05$ vs. chronic $\mathrm{CAD}$ and control groups; ${ }^{\mathrm{b}} \mathrm{P}<0.05$ vs. control group. MDA, malodialdehyde; MDA-SA, malodialdehyde with sodium azide; ACS, acute coronary syndrome; CAD; coronary artery disease.

of MDA in ACS and chronic CAD patients were markedly higher than in the control group $(\mathrm{P}<0.05)$. Furthermore, the MDA level in ACS patients was significantly higher than that in chronic CAD patients $(\mathrm{P}<0.05)$. The levels of MDA in the absence of sodium azide were as follows: in ACS patients, $633 \pm 39 \mathrm{nmol} / \mathrm{gHb}$; in chronic CAD patients, $490 \pm 33 \mathrm{nmol} / \mathrm{gHb}$ and in healthy controls, $173 \pm 19 \mathrm{nmol} / \mathrm{gHb}$, which revealed notable difference between the patient and control groups, and between the ACS and chronic CAD cases. A similar pattern of data were obtained with the zero time samples, revealing markedly high levels of MDA in ACS and chronic CAD patients compared with in the controls, and higher MDA levels in ACS patients in comparison with chronic CAD patients. Table III presents the percentage of MDA release from erythrocytes in patients and controls after the 120-min incubation and at zero time. The percentage of MDA release from erythrocytes, both at zero time and $120 \mathrm{~min}$, was significantly increased in the ACS and chronic CAD patients compared with in the healthy controls $(\mathrm{P}<0.05)$. In addition, this percentage was consider- 
Table III. Percentage of MDA release from erythrocytes at zero time and 120 min after incubation with $4 \mathrm{mM} \mathrm{H}_{2} \mathrm{O}_{2}$.

\begin{tabular}{lcc}
\hline $\begin{array}{l}\text { Group } \\
(\mathrm{n}=30 / \text { group })\end{array}$ & $\begin{array}{c}\text { \% MDA release } \\
\text { (zero time) }\end{array}$ & $\begin{array}{c}\text { \% MDA release } \\
(120 \mathrm{~min})\end{array}$ \\
\hline Control & $35.0 \pm 5.00$ & $42.0 \pm 4.80$ \\
Chronic CAD patients & $42.0 \pm 4.70^{\mathrm{a}}$ & $57.0 \pm 9.90$ \\
ACS patients & $51.0 \pm 6.40^{\mathrm{b}}$ & $64.0 \pm 9.30$
\end{tabular}

All data are expressed as means \pm standard error of the mean, $\mathrm{n}=30$ /group. ${ }^{\mathrm{a}} \mathrm{P}<0.05$ vs. chronic $\mathrm{CAD}$ and control groups; ${ }^{\mathrm{b}} \mathrm{P}<0.05$ vs. control group. MDA, malodialdehyde; ACS, acute coronary syndrome; CAD; coronary artery disease.

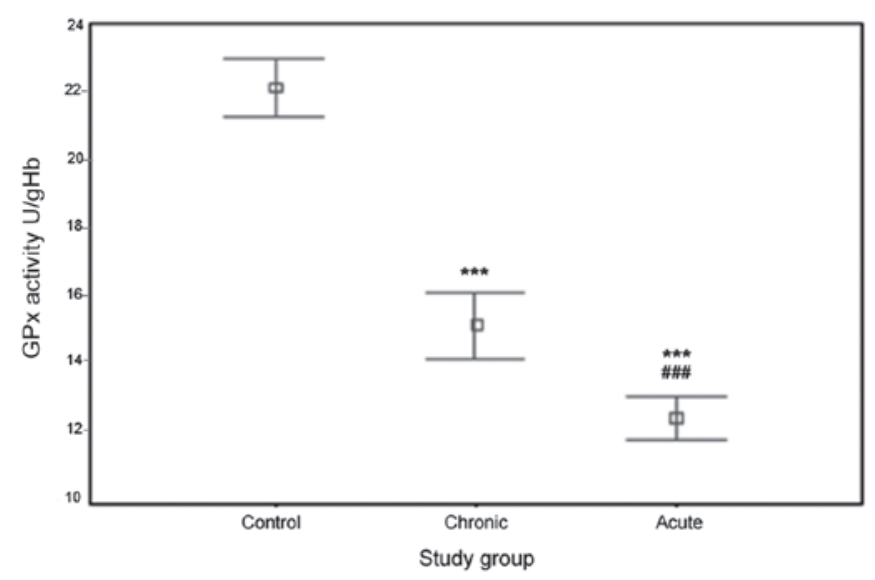

Figure 2. Evaluation of erythrocyte GPx activity in patients with ACS and chronic coronary disease compared with healthy controls. Data are expressed as means \pm standard error of the mean. GPx, glutathione peroxidase; ACS, acute coronary syndrome. ${ }^{* * *} \mathrm{P}<0.0001$ vs. control; ${ }^{\# \#} \mathrm{P}<0.0001$ vs. chronic.

ably higher in the ACS patients when compared with that in the chronic $\mathrm{CAD}$ patients $(\mathrm{P}<0.05)$.

Evaluation of erythrocyte GPX activity in patient groups and healthy controls. The results of erythrocyte GPx activity in the ACS/chronic CAD patients and controls are depicted in Fig. 2. GPx activity values in the three groups were $12.52 \pm 1.76 \mathrm{U} / \mathrm{gHb}$ for ACS patients, $15.14 \pm 2.52 \mathrm{U} / \mathrm{gHb}$ for chronic CAD patients and $22.12 \pm 2.12 \mathrm{U} / \mathrm{gHb}$ for controls. As illustrated in the Figure, the activity of erythrocyte GPx of ACS and chronic CAD patients was significantly lower than that in healthy controls $(\mathrm{P}<0.0001)$. Furthermore, the activity of this enzyme in ACS patients was markedly lower than that in chronic CAD patients $(\mathrm{P}<0.0001)$.

Comparison of plasma TAC in patient and control groups. Significant differences were observed between the TAC of plasma in the ACS, chronic CAD and healthy control groups. The values of plasma TAC were as follows: in ACS patients, $1.02 \pm 0.18 \mathrm{mmol} / \mathrm{l}$; in chronic CAD patients, $1.24 \pm 0.16 \mathrm{mmol} / \mathrm{l}$; and in controls, $1.52 \pm 0.23 \mathrm{mmol} / \mathrm{l}$. Fig. 3 illustrates the significant reduction in the TAC of plasma in ACS and chronic CAD patients compared with that in

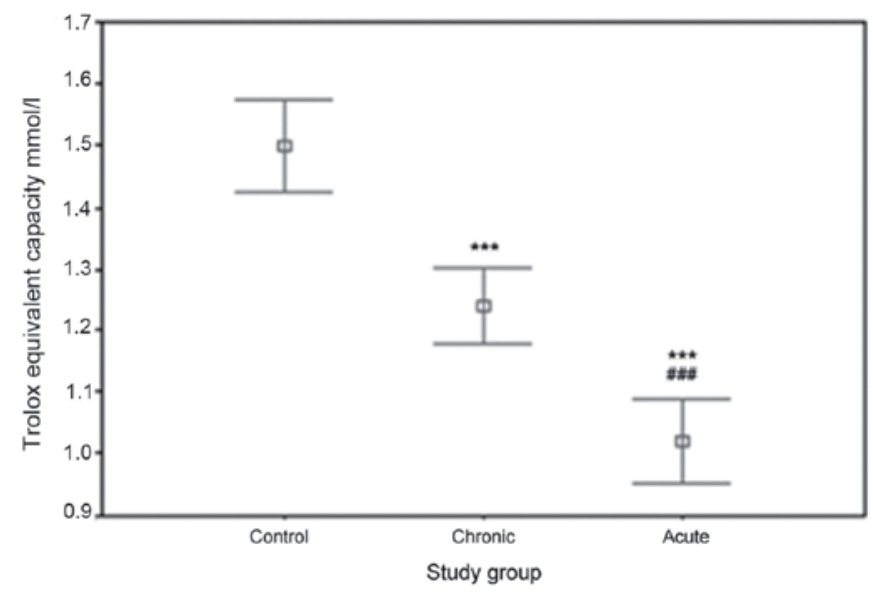

Figure 3. Representation of TAC of plasma in patients with ACS and chronic coronary disease compared with healthy controls. Data are expressed as means \pm standard error of the mean. TAC, total antioxidant capacity; ACS, acute coronary syndrome. ${ }^{* * *} \mathrm{P}<0.0001$ vs. control; ${ }^{\# \#} \mathrm{P}<0.0001$ vs. chronic.

Table IV. Association between the number of stenotic vessels and oxidative status in chronic coronary artery disease patients.

\begin{tabular}{lcccc}
\hline & \multicolumn{4}{c}{ Erythrocyte } \\
$\begin{array}{lcccc}\text { Group } \\
\text { (n=30/group) }\end{array}$ & $\begin{array}{c}\text { MDA } \\
\text { nmol/gHb }\end{array}$ & $\begin{array}{c}\text { GPx, } \\
\text { U/gHb }\end{array}$ & $\begin{array}{c}\text { GSH } \\
\text { mol/gHb }\end{array}$ & $\begin{array}{c}\text { TAC } \\
\text { mmol/1 }\end{array}$ \\
\hline $\begin{array}{l}\text { Control } \\
\begin{array}{l}\text { Patients with } \\
\text { one-vessel disease }\end{array}\end{array}$ & $609 \pm 41$ & $22.1 \pm 2.20$ & $10.6 \pm 0.48$ & $1.5 \pm 0.20$ \\
$\begin{array}{l}\text { Patients with } \\
\text { two-vessel disease }^{\mathrm{n}}\end{array}$ & $900 \pm 35^{\mathrm{b}}$ & $14.7 \pm 1.60$ & $6.7 \pm 0.48$ & $1.06 \pm 0.16$ \\
$\begin{array}{l}\text { Patients with } \\
\text { three-vessel disease }\end{array}$ & $991 \pm 43^{\mathrm{c}}$ & $13.9 \pm 3.70$ & $6.3 \pm 0.53$ & $0.15 \pm 0.91$ \\
\hline
\end{tabular}

TAC, Total antioxidant capacity of plasma. All data are expressed as mean \pm standard error of the mean; P-value $<0.05$. n, no. of subjects. ${ }^{\mathrm{a}} \mathrm{P}<0.05$, when compared with control group. ${ }^{\mathrm{b}} \mathrm{P}<0.05$, when compared with patients with one vessel disease and control group. ${ }^{\mathrm{c}} \mathrm{P}<0.05$, when compared with other three groups. MDA, malondialdehyde; GPx, glutathione peroxidase; GSH, reduced glutathione.

controls $(\mathrm{P}<0.0001)$. A significant reduction in the plasma TAC of ACS patients compared with that of chronic CAD patients was also revealed $(\mathrm{P}<0.0001)$.

Evaluation of association between the number of stenotic vessels and oxidative status in chronic CAD patients. The results of oxidative and antioxidative parameters measured in these three groups are presented in Table IV. From these data a significant increase in MDA (120 min) level $(\mathrm{P}<0.05)$ and notable decreases in GSH concentration, TAC and erythrocyte GPx activity were observed in patients with triple-vessel disease compared with the patients with double and single-vessel disease and healthy controls. Additionally, an augmented level of MDA $(\mathrm{P}<0.05)$ and reduced GSH and TAC levels as well as GPx activity were identified in patients with double stenotic vessels in comparison with the single 
stenosis and control groups. Similar data were observed with single stenotic patients as compared with healthy subjects.

\section{Discussion}

The main purposes of the present investigation were to compare plasma oxidative status and RBC susceptibility to oxidative stress in patients with CAD and healthy controls. It was identified that the levels of erythrocyte GSH in ACS and chronic CAD patients was markedly lower than in healthy controls. Furthermore, the level was also lowered in ACS patients as compared with in chronic CAD patients. Similar results have been reported by other groups with regard to significant decreases in the level of GSH in CAD patients (23-25).

The present findings indicated that both the levels of MDA and the percentage of MDA release from erythrocytes in ACS and chronic CAD patients were significantly increased compared with in the healthy controls. In addition, these two parameters in ACS patients were significantly higher than in chronic CAD patients. These data suggest that erythrocyte membranes in ACS patients are more readily oxidized in comparison to those in chronic CAD patients and healthy subjects; and furthermore that the susceptibility of erythrocyte membranes to oxidation in chronic CAD patients is higher than that in healthy subjects. Generally, increases in MDA level and the percentage of MDA release from erythrocytes in patients appeared to be due to decreased erythrocyte GSH content relative to that in healthy subjects. Since a high concentration of polyunsaturated fatty acids in the phospholipid membrane of RBCs may lead to more extensive oxidation of the membrane lipids (26), it is necessary to consider the differences in erythrocytes membrane composition between patients groups and controls.

The present findings are also in accordance with a number of studies reporting an increased level of MDA in CAD and myocardial infarction patients compared with healthy control groups $(25,27,28)$. Amaki et al (29) identified that the serum levels of circulating MDA-modified LDL in patients with CAD were significantly higher than in patients without CAD, indicating the use of this parameter as a diagnostic marker for advanced atherosclerosis.

The results of the present study revealed that patients with ACS and chronic CAD exhibited lower erythrocyte GPx and TAC activity compared with healthy controls. Decreased erythrocyte GPx and TAC activity in the patient groups appeared to be correlated with induced oxidative conditions, leading to extensive oxidative stress and increased susceptibility of the erythrocyte membrane to this oxidant status.

These present data are also concordant with the results of Serdar et al (30), who reported decreased activities of antioxidant enzymes including erythrocyte GPx and some other antioxidant enzymes as well as a decreased concentration of antioxidant factors in patients with CAD. In another study, Serdar et al (31) investigated the correlation between total sialic acid (TSA) concentration in serum and antioxidative and oxidative markers including plasma MDA, paraoxonase, GPx, vitamin $\mathrm{C}$ and vitamin $\mathrm{E}$ in CAD patients. They identified a positive correlation between TSA and these parameters. Furthermore, their study revealed a significant reduction of antioxidant parameters in the patients with
CAD. Different groups have also reported an imbalance in the levels of peroxiredoxin-1 (an antioxidant enzyme) and GPx in the blood of patients with CAD, and existence of a direct correlation between low GPx activity and high levels of ROS in ACS patients $(32,33)$. Collectively, these findings suggest a potential contribution of inefficient protection against oxidant-mediated damage to increased clinical risk of CAD. Further study has revealed marked increases in the levels of oxidized-LDL and GPx expression and activity in ACS patients in comparison with patients with stable CAD and healthy controls (34). According to this previous study, GPx level may be upregulated in response to an alteration in oxidative stress during ACS. According to the current data, patients with triple-vessel stenosis had significantly increased levels of MDA and notably decreased GSH, TAC and GPx activities in comparison with patients with double and single vessel disease and healthy controls. These parameters also exhibited the same patterns in double vessel disease patients when compared with the single vessel disease patients and controls. Such findings suggest that the number of narrowed vessels may have positive correlation with deteriorated oxidative condition in chronic CAD patients; the greater the number of stenotic vessels, the higher the oxidative stress induced in these patients.

It was apparent that ACS patients had deteriorated oxidant and antioxidant conditions compared with chronic CAD patients and healthy controls. The significant differences between ACS and chronic CAD patients suggested that the chronic form of disease had greater probability of improvement in antioxidative processes to ameliorate oxidative stress. Meanwhile, acute syndrome likely has insufficient time to enhance the protective processes and adaptive mechanisms.

This present study sheds light on the association between acute and chronic conditions in CAD and the oxidative status of affected patients. The results indicate that the chronic form of disease is more adapted to oxidative stress in comparison to the acute form, indicating the need to reduce oxidative status in ACS patients. However, in both ACS and chronic CAD patients, high erythrocyte membrane susceptibility, low antioxidant capacity and decreased function of antioxidative systems were detected compared with in the healthy controls. Therefore, the use of exogenous antioxidants may have potential therapeutic benefits in reducing oxidant status in these patients. However, there remains a need for detailed study of other key pathways involved in atherogenesis, including those associated with pro-inflammatory markers.

\section{Acknowledgements}

Not applicable.

\section{Funding}

The present study was supported by internal funding from Shahid Beheshti Univesity of Medical Sciences, Tehran, Iran.

\section{Availability of data and materials}

All datasets used or analyzed during this study are available from the corresponding authors on reasonable request. 


\section{Authors' contributions}

$\mathrm{AB}$ designed the study and aided in writing the manuscript. SR assisted in drafting the manuscript and revising it critically for intellectual content. AD performed the experiments. HS was the co-supervisor together with $A B$ and aided in collecting the samples and interpreting the results. FKB aided with manuscript writing and interpreting the data.

\section{Ethics approval and consent to participate}

Written informed consent was obtained and signed by all patients who agreed to participate in the study.

\section{Patient consent for publication}

The patients provided written informed consent for the publication of any associated data and accompanying images.

\section{Competing interests}

The authors declare that they have no competing interests.

\section{References}

1. Pathak LA, Shirodkar S, Ruparelia R and Rajebahadur J: Coronary artery disease in women. Indian Heart J 69: 532-538, 2017.

2. Wong ND: Epidemiological studies of CHD and the evolution of preventive cardiology. Nat Rev Cardiol 11: 276-289, 2014.

3. Hansson GK: Inflammation, atherosclerosis, and coronary artery disease. N Engl J Med 352: 1685-1695, 2005.

4. Badimon L and Vilahur G: Thrombosis formation on atherosclerotic lesions and plaque rupture. J Intern Med 276: 618-632, 2014.

5. Zaman AG, Helft G, Worthley SG and Badimon JJ: The role of plaque rupture and thrombosis in coronary artery disease. Atherosclerosis 149: 251-266, 2000.

6. Wick G and Grundtman C (eds): Inflammation and Atherosclerosis. Vol I. Springer-Verlag Wien, Austria, 2011.

7. Cervantes Gracia K, Llanas-Cornejo D and Husi H: CVD and oxidative stress. J Clin Med 6: 22, 2017.

8. Vogiatzi G, Tousoulis D and Stefanadis C: The role of oxidative stress in atherosclerosis. Hellenic J Cardiol 50: 402-409, 2009.

9. Bonomini F, Tengattini S, Fabiano A, Bianchi R and Rezzani R: Atherosclerosis and oxidative stress. Histol Histopathol 23 : 381-390, 2008

10. Stocker R and Keaney JF: Role of oxidative modifications in atherosclerosis. Physiol Rev 84: 1381-1478, 2004.

11. Madamanchi NR, Hakim ZS and Runge MS: Oxidative stress in atherogenesis and arterial thrombosis: The disconnect between cellular studies and clinical outcomes. J Thromb Haemost 3: 254-267, 2005.

12. Valko M, Rhodes CJ, Moncol J, Izakovic M and Mazur M: Free radicals, metals and antioxidants in oxidative stress-induced cancer. Chem Biol Interact 160: 1-40, 2006.

13. Shao B and Heinecke JW: HDL, lipid peroxidation, and atherosclerosis. J Lipid Res 50: 599-601, 2009.

14. Lee SE and Park YS: Role of lipid peroxidation-derived $\alpha$, $\beta$-unsaturated aldehydes in vascular dysfunction. Oxid Med Cell Longev 2013: 629028, 2013.

15. Ahmadinejad F, Geir Møller S, Hashemzadeh-Chaleshtori M, Bidkhori G and Jami M-S: Molecular Mechanisms behind Free Radical Scavengers Function against Oxidative Stress. Antioxidants 6: 51, 2017.

16. Beutler E, Duron O and Kelly BM: Improved method for the determination of blood glutathione. J Lab Clin Med 61: 882-888, 1963.
17. Kadiiska MB, Gladen BC, Baird DD, Germolec D, Graham LB, Parker CE, Nyska A, Wachsman JT, Ames BN, Basu S, et al: Biomarkers of oxidative stress study II: Are oxidation products of lipids, proteins, and DNA markers of $\mathrm{CCl} 4$ poisoning? Free Radic Biol Med 38: 698-710, 2005.

18. Amatuzio DS, Grande F and Wada S: The cyanmethemoglobin method for hemoglobin determination. Minn Med 45: 378-381, 1962.

19. Cynamon HA, Isenberg JN and Nguyen $\mathrm{CH}$ : Erythrocyte malondialdehyde release in vitro: A functional measure of vitamin $\mathrm{E}$ status. Clin Chim Acta 151: 169-176, 1985.

20. Andersen HR, Nielsen JB, Nielsen F and Grandjean P: Antioxidative enzyme activities in human erythrocytes. Clin Chem 43: 562-568, 1997.

21. Sonet J, Bierla K, Bulteau A-L, Lobinski R and Chavatte L: Comparison of analytical methods using enzymatic activity, immunoaffinity and selenium-specific mass spectrometric detection for the quantitation of glutathione peroxidase 1 . Anal Chim Acta 1011: 11-19, 2018

22. Miller NJ, Rice-Evans C, Davies MJ, Gopinathan V and Milner A: A novel method for measuring antioxidant capacity and its application to monitoring the antioxidant status in premature neonates. Clin Sci (Lond) 84: 407-412, 1993.

23. Damy T, Kirsch M, Khouzami L, Caramelle P, Le Corvoisier P, Roudot-Thoraval F, Dubois-Randé JL, Hittinger L, Pavoine $C$ and Pecker F: Glutathione deficiency in cardiac patients is related to the functional status and structural cardiac abnormalities. PLoS One 4: e4871, 2009.

24. Kaur K, Bedi G, Kaur M, Vij A and Kaur I: Lipid peroxidation and the levels of antioxidant enzymes in coronary artery disease. Indian J Clin Biochem 23: 33-37, 2008.

25. Pamplona R: Membrane phospholipids, lipoxidative damage and molecular integrity: A causal role in aging and longevity. Biochim Biophys Acta 1777: 1249-1262, 2008.

26. Kumar E, Mukherjee R, Senthil R, Parasuraman S and Suresh B: Evaluation of oxidative stress and antioxidant status in patients with cardiovascular disease in rural populations of the nilgiris, South India. ISRN pharmacol 2012: 941068, 2012.

27. Bhat MA, Mahajan N and Gandhi G: Oxidative stress status in coronary artery disease patients. Int J Life Sc Bt Pharm Res 1: 236-243, 2012.

28. Surekha RH, Srikanth BB, Jharna P, Ramachandra RV, Dayasagar RV and Jyothy A: Oxidative stress and total antioxidant status in myocardial infarction. Singapore Med J 48: 137-142, 2007.

29. Amaki T, Suzuki T, Nakamura F, Hayashi D, Imai Y, Morita H, Fukino K, Nojiri T, Kitano S, Hibi N, et al: Circulating malondialdehyde modified LDL is a biochemical risk marker for coronary artery disease. Heart 90: 1211-1213, 2004.

30. Serdar Z, Aslan K, Dirican M, Sarandöl E, Yeşilbursa D and Serdar A: Lipid and protein oxidation and antioxidant status in patients with angiographically proven coronary artery disease. Clin Biochem 39: 794-803, 2006.

31. Serdar Z, Yeşilbursa D, Dirican M, Sarandöl E and Serdar A: Sialic acid and oxidizability of lipid and proteins and antioxidant status in patients with coronary artery disease. Cell Biochem Funct 25: 655-664, 2007.

32. Vnukov VV, Sidorov RV, Milutina NP, Ananyan AA, Gvaldin DY, Sagakyants AB, Shlyk IF and Talalaev EP: Concentration of proinflammatory cytokines, peroxiredoxin-1 and glutathione peroxidase activity in the blood plasma of patients with coronary artery disease undergoing coronary artery bypass grafting. Adv Gerontol 30: 269-275, 2017 (In Russian).

33. Holley AS, Miller JH, Larsen PD and Harding SA: Relationship between glutathione peroxidase, platelet reactivity, and reactive oxygen species in an acute coronary syndrome population. Ann Clin Lab Sci 46: 639-644, 2016.

34. Holley A, Pitman J, Miller J, Harding S and Larsen P: Glutathione peroxidase activity and expression levels are significantly increased in acute coronary syndromes. J Investig Med 65: 919-925, 2017. 